\title{
Oral cancer in Brazil: dentists' lack of technical knowledge
}

Eliane TRAEBERT Jefferson TRAEBERT

Universidade do Sul de Santa Catarina - Unisul, Programa de Pós Graduação em Ciências da Saúde, Palhoça, SC, Brazil.

Declaration of Interests: The authors certify that they have no commercial or associative interest that represents a conflict of interest in connection with the manuscript

Corresponding Author:

Eliane Traebert

E-mail: elisazevedot@gmail.com

DOI: 10.1590/1807-3107BOR-2015.vol29.0069

Submitted: Feb 10, 2015

Accepted for publication: Mar 14, 2015

Last revision: May 05, 2015

\section{Dear Editor,}

A careful reading of the article "Oral cancer from a health perspective promotion: experience of the diagnosis network in Ceará" by Sousa et al. ${ }^{1}$ published in Brazilian Oral Research sparked our interest in debating the reported results.

As stated by Sousa et al., ${ }^{1}$ oral cancer prognosis is rare in Brazil. We have recently published an article showing that the 5-year survival rate in patients with cancer of the lips, mouth, and pharynx was only $33.3 \%$ in a cohort treated at the main referral center in the state of Santa Catarina, Brazil. ${ }^{2}$ The survival rate at 10 years was even lower (26.9\%).

As well argued by Sousa et al., ${ }^{1}$ although the oral cavity can be easily examined through visual and tactile inspection, which in theory could facilitate the detection of lesions in the initial asymptomatic phase, the diagnosis of oral cancer in this phase remains uncommon. It called our attention that "having never performed a biopsy" and the "lack of technical knowledge" were the main reasons stated by the surveyed dentists for not performing biopsies in their daily practice, and that $74.1 \%$ considered themselves unable to perform the procedure. Furthermore, anxiety was reported as the main feeling experienced by the dentists after the diagnosis of oral cancer in their patients.

The hypothesis that these results could represent the national reality raises the following questions: How can a country with more than 268,000 dentists graduated from 212 schools of dentistry ${ }^{3}$ overlook such a serious problem affecting its population? How are dental schools training dental professionals? Why does their vocational training process ignore a problem, such as oral cancer, which affect numerous patients? Is the dental curriculum adequate? Why are dentists not recognized by the society as the professionals capable of handling such a problem? The above mentioned as well as other similar questions need urgent answers.

The shortage of dental professionals and dental schools can definitely be ruled out as a possible factor.

Thus, the mission, values, concepts, and objectives of Brazilian dental schools need to be reviewed. Schools should prepare dental professionals with the view point of population-oriented health care so that they have the required skills and expertise to deal with major health problems that afflict its population, certainly including oral cancer.

Sincerely, 


\section{References}

1. Sousa FR, Silva MRF, Fernandes CP, Silva PGB, Alves APNN. Oral cancer from a health promotion perspective: experience of a diagnosis network in Ceará. Braz Oral Res. 2014;28 Spec. pii: S1806-83242014000200006. doi: 10.1590/1807-3107BOR-2014.vol28.0018. Epub 2014 Jun 20.
2. Schneider IJC, Flores ME, Nickel DA, Martins LGT, Traebert J. Survival rates of patients with cancer of the lip, mouth and pharynx: a cohort study of 10 years. Rev Bras Epidemiol. 2014;17(3):680-91.

3. Conselho Federal de Odontologia. Estatísticas. [cited 2015 Feb 4]. Available from: www.cfo.org.br/wp-content/ uploads/2011/06/ Total_Geral_Brasil.pd 